\title{
A novel TLR2 agonist from Bordetella pertussis is a potent adjuvant that promotes protective immunity with an acellular pertussis vaccine
}

\author{
A Dunne ${ }^{1,3}$, LA Mielke ${ }^{2,3}$, AC Allen ${ }^{2}$, CE Sutton ${ }^{2}$, R Higgs $^{2}$, CC Cunningham ${ }^{1}$, SC Higgins ${ }^{2}$ and \\ KHG Mills ${ }^{2}$
}

Bordetella pertussis causes whooping cough, a severe and often lethal respiratory infection in infants. A recent resurgence of pertussis has been linked with waning or suboptimal immunity induced with acellular pertussis vaccines (Pa) that were introduced to most developed countries in the 1990s because of safety concerns around the use of wholecell pertussis vaccines $(\mathrm{Pw})$. Pa are composed of individual $B$. pertussis antigens absorbed to alum and promote strong antibody, T helper type 2 (Th2) and Th17 responses, but are less effective at inducing cellular immunity mediated by Th1 cells. In contrast, Pw, which include endogenous Toll-like receptor (TLR) agonists, induce Th1 as well as Th17 responses. Here we report the identification and characterization of novel TLR2-activating lipoproteins from $B$. pertussis. These proteins contain a characteristic $\mathrm{N}$-terminal signal peptide that is unique to Gram-negative bacteria and we demonstrate that one of these lipoproteins, BP1569, activates murine dendritic cells and macrophages and human mononuclear cells via TLR2. Furthermore, we demonstrated that a corresponding synthetic lipopeptide LP1569 has potent immunostimulatory and adjuvant properties, capable of enhancing Th1, Th17, and IgG2a antibody responses induced in mice with an experimental $\mathrm{Pa}$ that conferred superior protection against $B$. pertussis infection than an equivalent vaccine formulated with alum.

\section{INTRODUCTION}

The bacterium Bordetella pertussis is the causative agent of whooping cough, a severe and debilitating respiratory tract infection affecting infants and young children. Whooping cough (pertussis) still accounts for over 200,000 infant deaths annually, mostly in developing countries. The disease was largely controlled in developed countries through vaccination with whole-cell pertussis vaccines $(\mathrm{Pw})$ that were introduced in the 1950s. However, these vaccines were associated with unacceptable side effects and were replaced in many countries in the 1990s by acellular pertussis vaccines $(\mathrm{Pa})$, composed of individual $B$. pertussis antigens absorbed to alum as the adjuvant. $^{1,2}$ Although the number of cases of pertussis continued to decline following introduction of $\mathrm{Pa}$, in recent years there have been alarming increases in the incidence of disease not only in infants but also in adolescents and young adults. This has been attributed to antigenic variation in protective antigens or waning and ineffective immunity induced with current $\mathrm{Pa}^{3}{ }^{3,4}$ The resurgence in pertussis has consequently called into question the level of protection provided by current vaccines and highlighted the need for a better understanding of the molecular mechanisms underlying the pathogenesis of the infection and the mechanisms of natural and vaccine-induced immunity to $B$. pertussis. Studies in children and mice have demonstrated that Pa promote the induction of Thelper type 2 (Th2) and Th17 cells, ${ }^{5-8}$ and this has been attributed to the use of alum as the adjuvant. ${ }^{9}$ In contrast, $\mathrm{Pw}$ induce Th1 and Th17 responses and confer a higher level of protection against infection in mice and in children and this is thought to reflect the presence of

\footnotetext{
${ }^{1}$ Molecular Immunology Group, School of Biochemistry and Immunology and Immunology Research Centre, Trinity Biomedical Sciences Institute, Trinity College Dublin, Dublin, Ireland and ${ }^{2}$ Immune Regulation Research Group, School of Biochemistry and Immunology and Immunology Research Centre, Trinity Biomedical Sciences Institute, Trinity College Dublin, Dublin, Ireland. Correspondence: KHG Mills (kingston.mills@tcd.ie)

${ }^{3}$ The first two authors contributed equally to this work.
} 
B. pertussis-derived pathogen-associated molecular patterns, including agonists for Toll-like receptors (TLRs). ${ }^{2}$

TLRs belong to a large family of pattern recognition receptors that have evolved for innate immune recognition of conserved microbial products. ${ }^{10} \mathrm{We}$ have previously demonstrated that TLR4, the receptor for lipopolysaccharide (LPS), plays a key role in clearance of a primary infection with $B$. pertussis and in immunity generated with Pw. ${ }^{11,12}$ This may in part reflect the immunostimulatory activity of LPS in live and killed bacteria that binds to TLR4 and promotes production of innate inflammatory cytokines, including interleukin (IL)-1, IL-6, IL-12, and IL-23. Although it is widely believed that LPS acts as an adjuvant within the Pw, it is also a key mediator of toxicity, including the fever and seizures observed following vaccination of infants with $\mathrm{Pw}^{13}$ We have also demonstrated that activation of another pattern recognition receptor, NLRP3, by adenylate cyclase toxin from $B$. pertussis leads to protective adaptive immune responses via IL-1 and IL-17 production and this requires cooperation with TLR agonists. ${ }^{14}$

A number of Gram-negative bacteria have been shown to express ligands for TLR2. TLR2 forms a heterodimer with either TLR1 or TLR6 to recognize triacylated or diacylated lipoproteins, respectively. ${ }^{15-17}$ These lipoproteins contain a common N-terminal signal sequence consisting of a positively charged region followed by a hydrophobic region of 7-22 residues and finally a lipobox within the first 40 residues from the N-terminus with the consensus sequence [LVI][ASTVI][ASG][C]. ${ }^{18-20}$ During biosynthesis of the lipoprotein, an acyl group such as palmytic acid is covalently attached to the conserved cysteine residue in the lipobox and the signal sequence is enzymatically cleaved, leaving an exposed acylcoupled N-terminus. Structural studies have demonstrated that the acyl group on a lipopeptide physically interacts with TLR2 to activate the receptor and subsequent downstream signaling pathways. $^{21}$

In this study, we have used mass spectroscopy and bioinformatic approaches to identify six putative TLR-activating lipoproteins from $B$. pertussis. We demonstrate that at least two of these novel proteins specifically activate TLR2 and drive potent pro-inflammatory cytokine production. Furthermore, we demonstrate that a corresponding synthetic lipopeptide of one of the lipoproteins has potent adjuvant properties, promoting protective Th1 and Th17 responses against $B$. pertussis infection in vivo when coadministered with pertussis antigens. Our findings demonstrate that combining protective antigens with an adjuvant based on an endogenous TLR2 ligand from B. pertussis has considerable potential for the development of a more effective vaccine capable of generating protective immunity against this re-emerging human pathogen.

\section{RESULTS}

Identification, cloning, expression, and purification of TLR2-activating lipoproteins from $B$. pertussis

Putative $B$. pertussis lipoproteins were identified using the DOLOP database (http://www.mrc-lmb.cam.ac.uk/genomes/ dolop) that searches for the presence of the N-terminal signal peptide found in lipoproteins from Gram-negative bacteria. The sequences of uncharacterized proteins identified in a mass spectroscopy analysis of secreted proteins from B. pertussis ${ }^{22}$ were used as a source for this screen in order to ensure that the proteins identified are indeed expressed proteins. The highest scoring proteins are listed in Table $\mathbf{1}$ alongside putative homologs from other bacterial species. All six proteins contain the characteristic positively charged region followed by a stretch of hydrophobic amino acids and the lipobox containing the invariant cysteine residue to which the acyl group is attached during biosynthesis (Figure 1). Of note, BP1569, BP2508, and BP2992 share sequence similarity with lipoproteins from Neisseria meningitidis, Burkholderia pseudomallei, and Haemophilis influenzae, respectively, and BP2992 has sequence homology with an outer membrane lipoprotein from $H$. influenza that specifically activates TLR2. ${ }^{23}$

C-terminal histidine versions of the putative lipoproteins were constructed and expressed in Escherichia coli by isopropyl $\beta$-D-1-thiogalactopyranoside induction. BP1569 and BP2992 were successfully expressed and purified by nickel affinity chromatography followed by ion-exchange chromatography. Although BP2992 was found to be an immunologically active ligand for TLR2 (data not shown), we decided to focus on BP1569 because its expression levels were higher and we could generate significant quantities of the lipoprotein for more

Table 1 Putative lipoproteins from Bordetella pertussis

\begin{tabular}{|c|c|c|c|c|}
\hline Name & Primary accession & Electronic annotation & Size & Similar to \\
\hline BP0205 & Q7W0D8 & Putative lipoprotein & $\sim 19 \mathrm{kDa}$ & Hypothetical protein Q56428 from Thermus thermophilus \\
\hline BP1569 & Q7VXZ9 & Putative lipoprotein & $\sim 40 \mathrm{kDa}$ & Lipoprotein NMB0928 from Neisseria meningitidis \\
\hline BP3342 & Q7VU04 & Putative lipoprotein & $\sim 16 \mathrm{kDa}$ & $\begin{array}{l}\text { Lipoprotein Omp P6 from Haemophilus influenzae (verified } \\
\text { Toll-like receptor } 2 \text { (TLR2) agonist (14); 39\% sequence identity) }\end{array}$ \\
\hline BP3819 & Q7VSV3 & Uncharacterized & $\sim 25 \mathrm{kDa}$ & Poor matches \\
\hline BP2508 & Q9X6Z0 & Putative lipoprotein Synonym: OmlA & $\sim 19 \mathrm{kDa}$ & Lipoprotein OmIA from Burkholderia pseudomallei \\
\hline BP2992 & Q7VUT2 & Putative lipoprotein & $\sim 16 \mathrm{kDa}$ & $\begin{array}{l}\text { Outer membrane lipoprotein PCP from } H \text {. influenza (verified } \\
\text { TLR2 agonist (14); } 40 \% \text { sequence identity) }\end{array}$ \\
\hline
\end{tabular}


extensive in vitro and in vivo studies. Analysis of the purity of the BP1569 preparation revealed a strong band at $40 \mathrm{kDa}$, with a weaker band at $\sim 35 \mathrm{kDa}$ (Figure 2a). Western blotting suggested that the second band is a breakdown product of the full-length protein; proteolysis was not prevented by the presence of protease inhibitors. The lipoproteins co-purified

a

\begin{tabular}{|c|c|}
\hline Name & $\mathrm{N}$-terminal signal peptide: \\
\hline BP0205 & MQLTIR K LAYTLAFSTLV LAG $\underline{C}$ \\
\hline BP1569 & MRMNK R HAGASALMALAL LAG $\underline{C}$ \\
\hline BP3342 & MKSRIA K SLTIAALAAT LAA므 \\
\hline BP3819 & MSAPLDTPALRLNTRFATGIVLAGTLA LAGC \\
\hline BP2508 & MIARISLRPL K GLAVAVLAASA LTAC \\
\hline BP2992 & MNYMHSPSVVAGRARRLLAVAAVAGSVAV LAG드 \\
\hline
\end{tabular}

b

BP1569

MRMNKRHAGASALMALALLAGCSDVNQLLGNEESVDYKSTRRGDPLSIPP DLTQANNDPRYKAPASGTATYS̄OFQOQGLQOQASAGQNTNVLPERADMRV ERDGDLRWLVIERPPEQLFSKVVDFWTDTGFTVSVNNPQAGI IETDWAEN RAKIPESWLRQVLGSVLETAWDSGEREKFRTRVERVNGHTEIYITHNQML EKRVGSDGGQVQWTHGKEDPGLNAAMLARLMVYLGTDVDAARKLVAQAEA APQAPKVQSVRAEGAMLVVDESFDRAWRRVGVALDSGGFAVDDRDRSAGE YFVRYVDTDTGAQNEQPGFFSRLFSSDKKAQAPQYRIRLTGSGTQTQVTV LDANGQRDSSATAQRMLSVLKDKMV

\section{BP2992}

MNYMHSPSVVAGRARRLLAVAAVAGSVAVLAGCANPSASSGVYTYGQAQRE QIVRTGTVTGVRP ITI GGVILGALAGNAIENRAGKSSGYEITVRLDNGETRVVAOEADVPISVGORV QVISGAGPTRVTPY

Figure 1 Novel lipoproteins from Bordetella pertussis. (a) Signal peptides of potential lipopeptides from $B$. pertussis identified using DOLOP and confirmed using Signal $P$. (b) Full-length sequences of BP1569 and BP2992. The characteristic positively charged region and conserved lipobox [LVI][ASTVI][ASG][C] is highlighted in bold while the positively charges amino acids and conserved cysteine residue are underlined.

Figure 2 Bordetella pertussis lipoprotein BP1569 is a Toll-like receptor 2 (TLR2) agonist that promotes cytokine production and maturation of murine dendritic cells (DCs). (a) Sodium dodecyl sulfate-polyacrylamide gel electrophoresis (SDS-PAGE) analysis of BP1569 (lane 1: $10 \mathrm{ng}$ BP1569, lane 2: molecular weight (MW) markers) following nickel affinity and ion-exchange chromatography. (b) $\mathrm{DCs}$ from $\mathrm{C} 3 \mathrm{H} / \mathrm{HeJ}$ mice were cultured with BP1569 (100 and $\left.1000 \mathrm{ng} \mathrm{ml}^{-1}\right)$ for $24 \mathrm{~h}$ and cytokine production was measured by enzyme-linked immunosorbent assay (ELISA). (c) Surface expression of major histocompatibility complex class major histocompatibility complex class II (MHCII), CD80, and CD86 was determined by flow cytometry following treatment of $\mathrm{C} 3 \mathrm{H} / \mathrm{HeJ} D C$ with BP1569 (100 $\mathrm{ng} \mathrm{ml}^{-1}$; bold line) or medium only (gray line) for $24 \mathrm{~h}$. (d) DCs from C3H/HeJ mice were treated with BP1569 $\left(100 \mathrm{ng} \mathrm{ml}^{-1}\right)$ for $24 \mathrm{~h}$ with or without addition of anti-TLR2 antibody (T2.5; $2.5 \mu \mathrm{gml}^{-1}$ ). Tumor necrosis factor- $\alpha$ (TNF- $\alpha$ ) production was measured by ELISA. (e) BP1569 was treated with lipase from Aspergillus (As) or Pseudomonas $(\mathrm{Ps})$ at the indicated concentrations for $18 \mathrm{~h}$ at $37^{\circ} \mathrm{C}$. Lipase-treated or untreated BP1569 (100 $\mathrm{ng} \mathrm{ml}^{-1}$ ) was used to stimulate bone marrowderived dendritic cells (BMDCs) from $\mathrm{C} 3 \mathrm{H} / \mathrm{HeJ}$ mice and after $24 \mathrm{~h}$ the concentrations of interleukin-6 (IL-6) in supernatants were quantified by ELISA. Results in $\mathbf{b}, \mathbf{d}$, and $\mathbf{e}$ are mean \pm 1 s.e.m. cytokine concentrations for triplicate cultures and are representative of three independent experiments. ${ }^{\star} P<0.05,{ }^{\star *} P<0.01,{ }^{* *} P<0.001$ vs. control (b) or vs. BP1569 alone (d, e)

with LPS, some of which we could remove using polymyxin B columns; however, because of the sticky nature of the lipid side chain, it proved impossible to obtain a preparation completely free of LPS. Therefore, we adopted a strategy of carrying out all initial studies with the lipoproteins in TLR4-defective cells or mice and then synthesized LPS-free lipopeptide versions for more thorough immunological analysis.

\section{BP1569 induces DC maturation and cytokine production in a TLR2 dependent manner}

We examined the capacity of $B$. pertussis lipoprotein to activate innate immune cells in vitro using bone marrow-derived

a

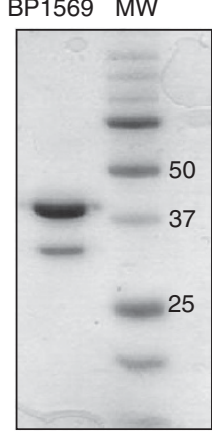

C
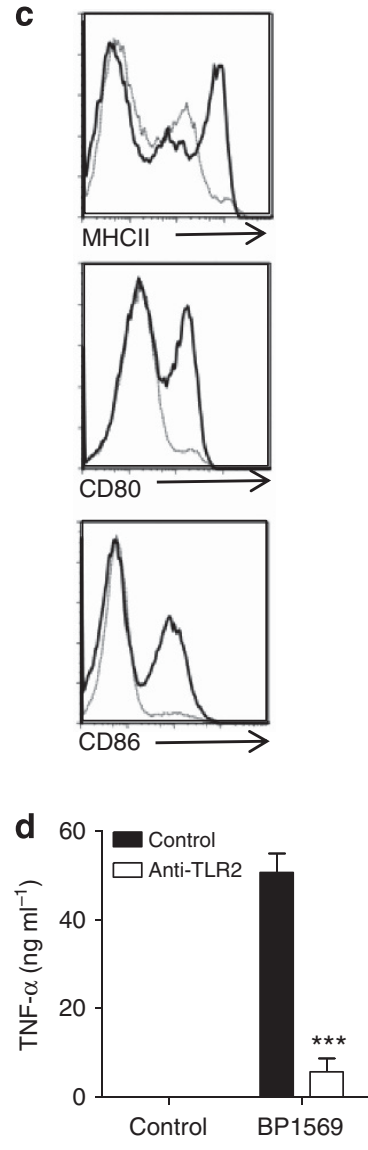
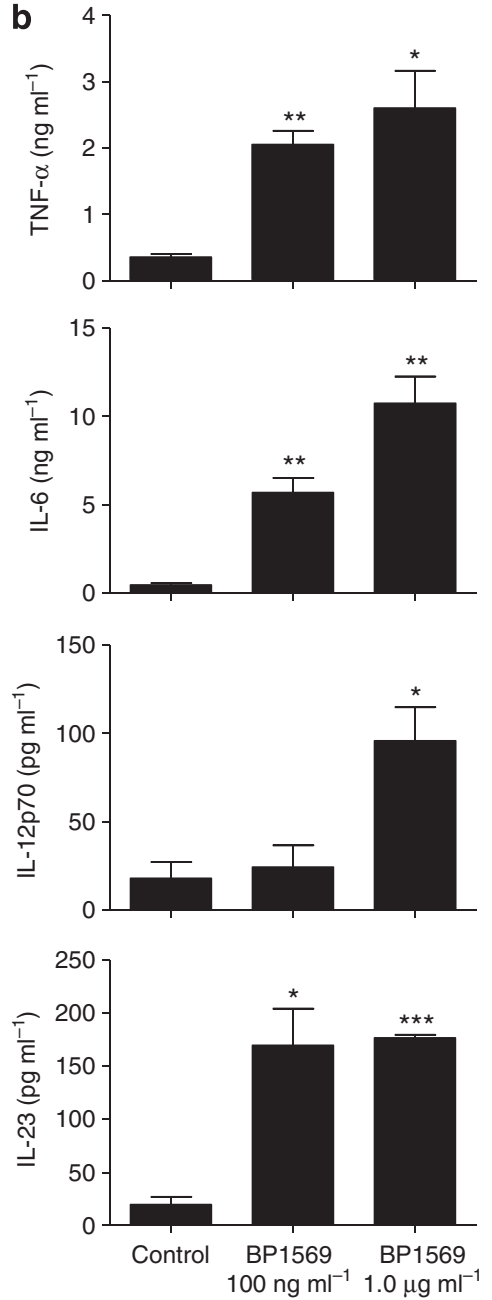

e

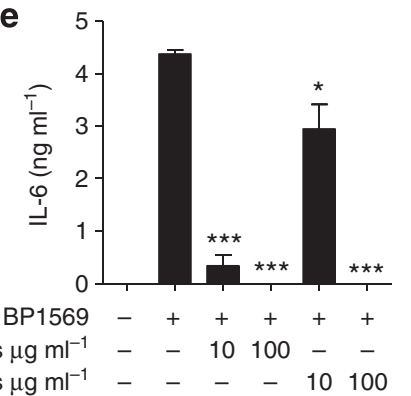


dendritic cells (DCs) from TLR4-defective, $\mathrm{C} 3 \mathrm{H} / \mathrm{HeJ}$ mice. BP1569 induced robust IL-6, IL-12, IL-23, and tumor necrosis factor- $\alpha($ TNF- $\alpha)$ production by DCs from $\mathrm{C} 3 \mathrm{H} / \mathrm{HeJ}$ mice (Figure 2b). Furthermore, stimulation of DCs with BP1569 for $24 \mathrm{~h}$ enhanced surface expression of major histocompatibility complex class II, CD80, and CD86 detectable by flow cytometry (Figure 2c).

We used blocking antibodies against TLR2 to determine whether the protein can activate TLR2 specifically. BP1569induced TNF- $\alpha$ production by DCs from $\mathrm{C} 3 \mathrm{H} / \mathrm{HeJ}$ mice was completely abrogated in the presence of the TLR2 blocking antibody (Figure 2d). BP1569-induced IL-6 and IL-12 were also reversed following addition of anti-TLR2 to the cultures (data not shown). We used lipase treatment to confirm that the immunostimulatory effects of BP1569 were because of the presence of the characteristic acyl side chain of the lipoprotein. The recombinant lipoprotein was incubated with two separate lipases for $18 \mathrm{~h}$ before stimulation of DCs. Lipase treatment abolished BP1569-induced IL-6 production (Figure 2e), but had no effect on cytokine production induced by the TLR9 agonist CpG (data not shown), confirming that BP1569 contains lipid side chains capable of triggering TLR2induced inflammatory cytokine production. These data demonstrate that BP1569 is a lipoprotein agonist for TLR2 and activates maturation and inflammatory cytokine production by murine DCs.

\section{BP1569 activates NF-кB and mitogen-activated protein kinase pathways downstream of TLR2}

Cytokine production by TLR2 requires activation of the transcription factors nuclear factor- $\kappa \mathrm{B}(\mathrm{NF}-\kappa \mathrm{B})$ and $\mathrm{p} 38$ mitogen-activated protein kinase. To determine whether BP1569 activates NF- $\mathrm{KB}$, HEK293T cells, stably expressing TLR2 but devoid of TLR4, were transfected with an NF- $\kappa B$ luciferase reporter construct. Untransfected HEK293T cells, which endogenously express TLR1 and TLR6, served as a control. BP1569 induced a dose-dependent increase in luciferase activity in HEK293T-TLR2 cells but not in HEK293T cells (Figure 3a). IL-8 production by TLR2-transfected HEK293T cells was also increased following stimulation with BP1569, linking activation of the NF- $\kappa B$ pathway with cytokine production (Figure $3 \mathbf{b}$ ). To assess activation of the mitogen-activated protein kinase pathway, spleen cells from $\mathrm{C} 3 \mathrm{H} / \mathrm{HeJ}$ mice were stimulated with BP1569. This treatment enhanced p38 phosphorylation 15 min following stimulation that was inhibited by addition of anti-TLR2 blocking antibody (Figure 3c). These results demonstrate that BP1569 induces TLR2-dependent activation of NF- $\mathrm{BB}$ and $\mathrm{p} 38$, the two a

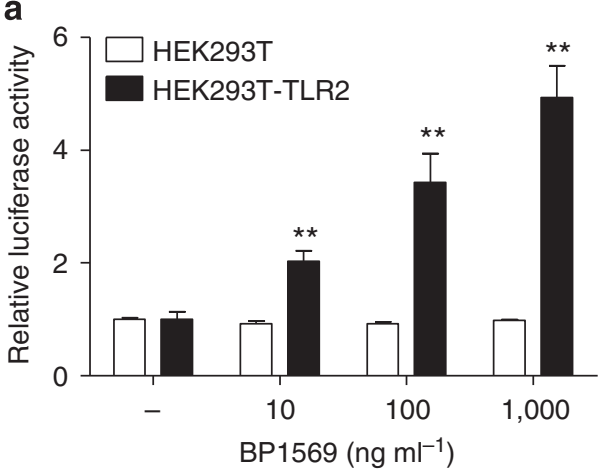

C

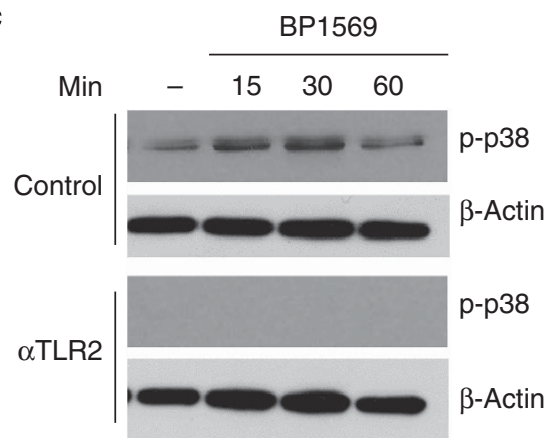

b

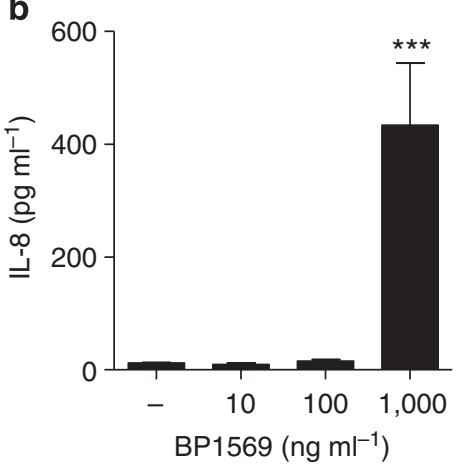

d

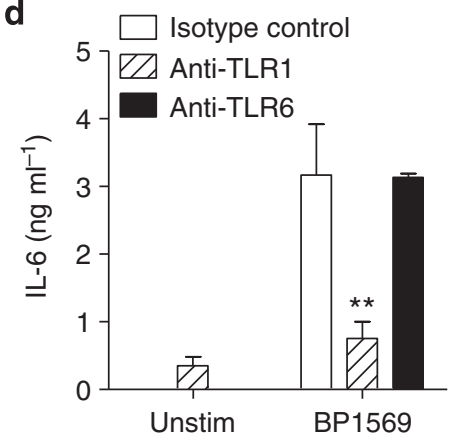

Figure 3 BP1569 activates nuclear factor- $\kappa B(N F-\kappa B)$ and mitogen-activated protein (MAP) kinase pathways. (a) HEK293T cells stably expressing human Toll-like receptor 2 (TLR2) or HEK293T cells without TLR2 were transfected with an NF-kB luciferase reporter construct before stimulation with increasing doses of BP1569. Luciferase activity was quantified after $24 \mathrm{~h}$. (b) HEK293T cells expressing human TLR2 were stimulated with increasing doses of BP1569 and interleukin-8 (IL-8) production was quantified after $24 \mathrm{~h}$. (c) Phosphorylation of p38 was assessed following stimulation of spleen cells from C3H/HeJ mice with BP1569 with or without addition anti-TLR2 antibody of $\left(\mathrm{T} 2.5 ; 2.5 \mu \mathrm{g} \mathrm{ml}^{-1}\right)$ or an isotype control. (d) Human peripheral blood mononuclear cells (PBMCs) were treated with BP1569 $\left(100 \mathrm{ng} \mathrm{ml}^{-1}\right)$ in the presence and absence of anti-TLR1 or anti-TLR6 neutralizing antibodies $\left(2 \mu \mathrm{g} \mathrm{ml}^{-1}\right)$. After $24 \mathrm{~h}$, the concentrations of IL-6 in supernatants were determined by enzyme-linked immunosorbent assay (ELISA). Results in a, $\mathbf{b}$, and d are mean \pm 1 s.e.m. values for $3-6$ cultures and are representative of two independent experiments. ${ }^{* *} P<0.01,{ }^{* * *} P<0.001$ vs. HEK293T (a) vs. control (b) or vs. isotype control (d). 
pathways shown to be required for TLR2-induced cytokine production. TLR agonists can bind to TLR $1 / 2$ or TLR $2 / 6$ heterodimers, and therefore we examined the role of these TLRs using specific blocking antibodies to human TLR1 and TLR6. Incubation of human peripheral blood mononuclear cells with a TLR1 blocking antibody significantly reduced BP1569induced IL-6 production, whereas an anti-TLR6 antibody had little effect, suggesting that BP1569 is triacylated rather than diacylated (Figure 3d).

\section{BP1569 induces innate inflammatory cytokines and is immunogenic in vivo}

Having demonstrated that BP1569 is capable of activating TLR2 in vitro, we determined whether the lipoprotein can induce proinflammatory cytokine responses in vivo. $\mathrm{C} 3 \mathrm{H} / \mathrm{HeJ}$ mice were injected intraperitoneally with BP1569 $(70 \mu \mathrm{g})$ and serum cytokines were measured after $3 \mathrm{~h}$. Significantly higher concentrations of IL- 6 and IL- 12 were detected in the serum of mice treated with the BP1569 compared with phosphatebuffered saline (PBS)-treated controls (Figure 4a).

We next examined the possibility that BP1569 was immunogenic in vivo and capable of inducing $B$. pertussisspecific immune responses. $\mathrm{C} 3 \mathrm{H} / \mathrm{HeJ}$ mice were injected into the footpad with BP1569 $(10 \mu \mathrm{g})$ diluted in PBS or with PBS only. After 7 days, the draining lymph node was harvested and the lymph node cells were stimulated with either BP1569 $\left(2 \mu \mathrm{g} \mathrm{ml}^{-1}\right)$ or heat-killed B. pertussis. BP1569-specific interferon- $\gamma$ (IFN- $\gamma)$ was induced at significant levels in mice immunized with BP1569 but not in mice immunized with PBS (Figure 4b). Furthermore, cells from immunized mice produced IFN- $\gamma$ upon restimulation with heat-killed B. pertussis, thus providing evidence that BP1569 is an antigenic, as well as an immunomodulatory, component of the bacteria (Figure 4c).

\section{Synthetic lipopeptide LP1569 induces inflammatory cytokines by human and murine innate immune cells}

Our results thus far demonstrate that BP1569 has immunomodulatory as well as antigenic properties, and the former is because of its ability to activate TLR2. In order to provide evidence of TLR2-mediated immunomodulatory activity, and to examine the adjuvant properties of the B. pertussis lipoprotein in vivo in conventional mice, we generated a synthetic lipopeptide version of BP1569. The lipopeptide, named LP1569 to distinguish it from the full-length protein, has the conserved cysteine residue palmitylated, followed by 11 amino acids of the protein sequence of BP1569. This represents the mature $\mathrm{N}$-terminus of the lipoprotein following removal of the signal peptide during biosynthesis. We first demonstrated that LP1569 stimulated DC activation. We found that LP1569 induced TNF- $\alpha$, IL-12p40, IL-12p70, IL-6, and IL-1 $\alpha$ a
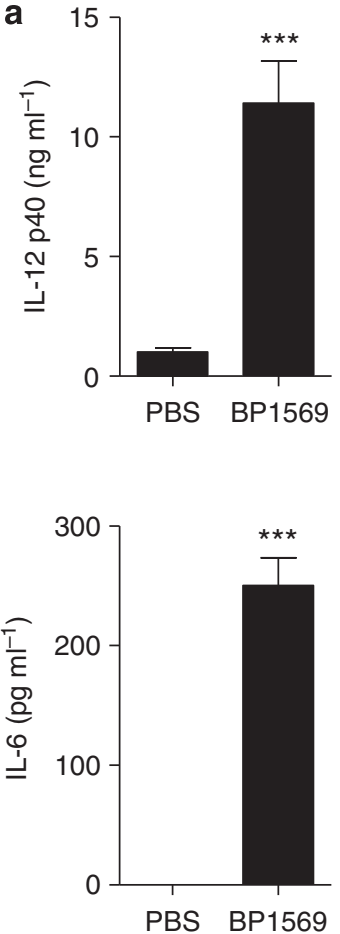

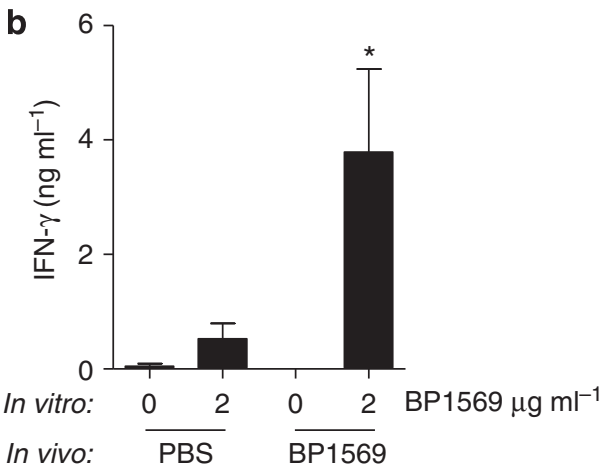

C

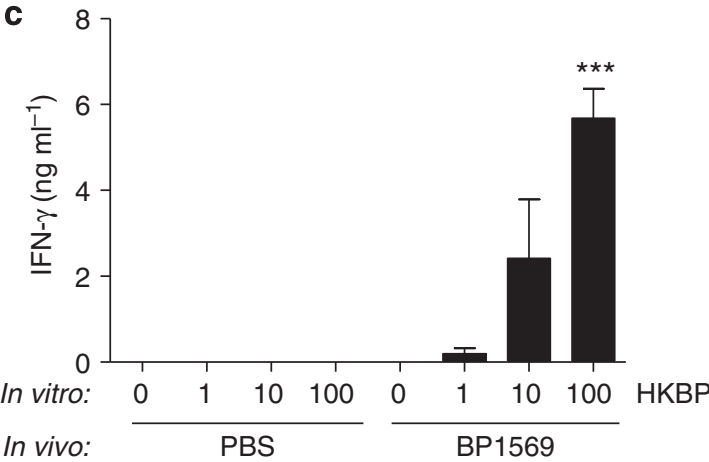

Figure 4 BP1569 induces innate cytokine and antigen-specific interferon- $\gamma$ (IFN- $\gamma$ ) production in vivo. (a) C3H/HeJ mice were injected intraperitoneally (i.p.) with BP1569 in phosphate-buffered saline (PBS; $70 \mu \mathrm{g}$ ) or PBS only. After $3 \mathrm{~h}$, serum interleukin (IL)-12 and IL-6 concentrations were quantified by enzyme-linked immunosorbent assay (ELISA). (b, c) C3H/HeJ mice were injected in the footpad with PBS or $10 \mu \mathrm{g}$ of BP1569. After 7 days, the draining lymph node was harvested and cells were stimulated in vitro with (b) either medium only or BP1569 $\left(2 \mu \mathrm{g} \mathrm{ml}^{-1}\right)$ or (c) escalating doses of heat-killed Bordetella pertussis (HKBP; 1,10 , or $100 \times 10^{6}$ per ml). Antigen-specific IFN- $\gamma$ was quantified by ELISA. Results are mean $\pm 1 \mathrm{~s} . e . \mathrm{m}$. cytokine concentrations for triplicate cultures (a) or mean \pm 1 s.e.m for 4 mice per group (b, $\mathbf{c})$ and are representative of two or three independent experiments. ${ }^{\star} P<0.05$ and ${ }^{* \star *} P<0.001$ vs. PBS. 


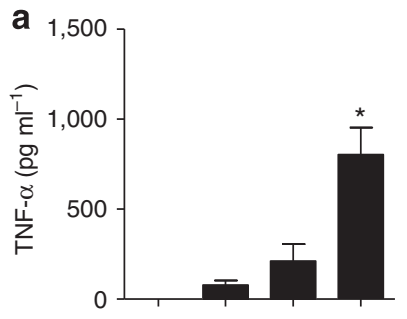

b
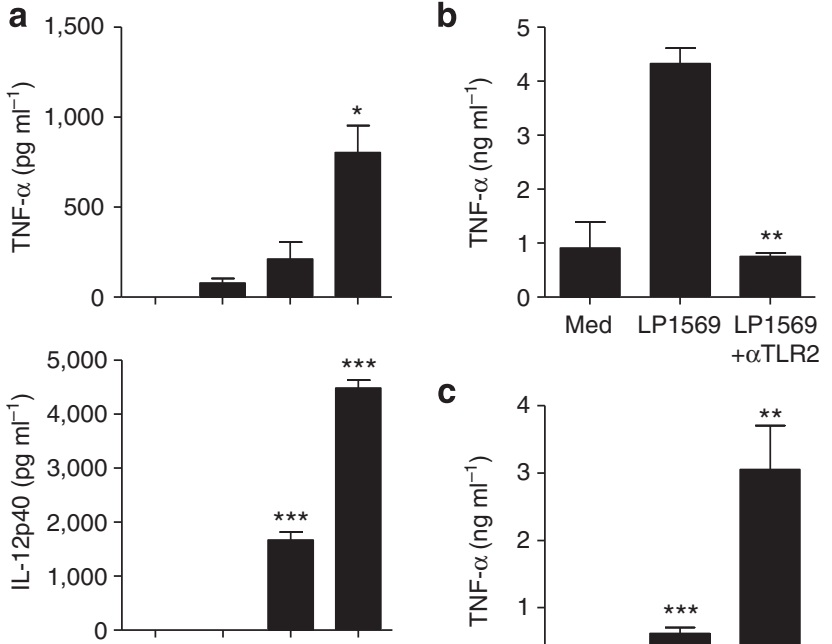

C
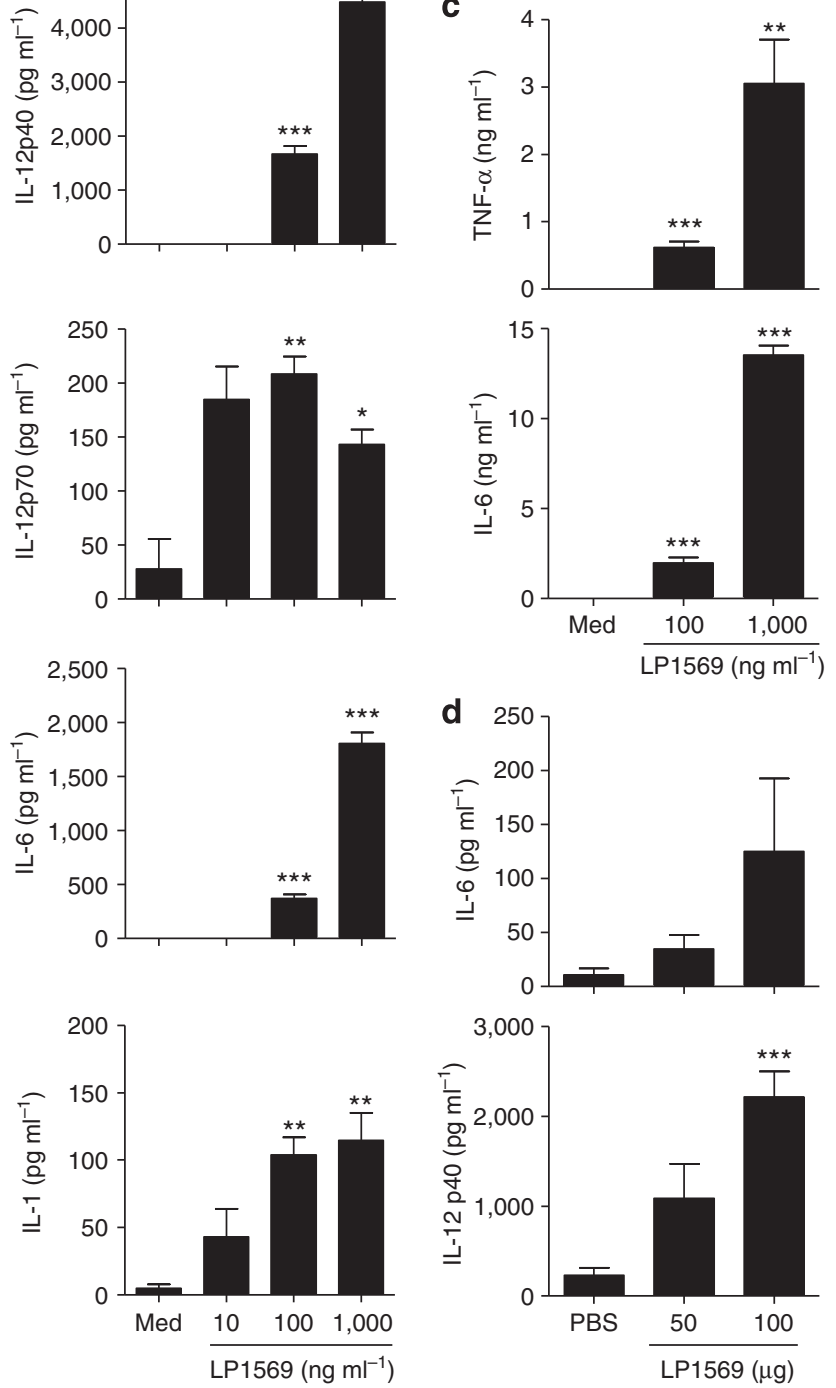

Figure 5 Synthetic lipopeptide LP1569 induces cytokine production by mouse dendritic cells (DCs) and human peripheral blood mononuclear cells (PBMCs). (a) DCs from C57BL/6 mice were stimulated with increasing concentrations of LP1569 or medium only (Med). After $6 \mathrm{~h}$, cytokine concentrations in supernatants were quantified by enzyme-linked immunosorbent assay (ELISA). (b) DCs from C57BL/6 mice were stimulated with LP1569 (500 $\left.\mathrm{ng} \mathrm{ml}^{-1}\right)$ alone or in the presence of anti-Tolllike receptor 2 (anti-TLR2; T2.5; $2.5 \mu \mathrm{g} \mathrm{ml}^{-1}$ ). After $24 \mathrm{~h}$ of culture, tumor necrosis factor- $\alpha$ (TNF- $\alpha$ ) production was quantified by ELISA. (c) Human PBMCs were treated with increasing concentrations of LP1569 for $24 \mathrm{~h}$ and TNF- $\alpha$ and interleukin-6 (IL-6) production was quantified by ELISA. (d) C57BL/6 mice were injected intraperitoneally (i.p.) with LP1569 (50 or $100 \mu \mathrm{g})$. After $3 \mathrm{~h}$, serum cytokines were quantified by ELISA. Results are mean \pm 1 s.e.m. cytokine concentrations for triplicate cultures and are representative of three independent experiments. ${ }^{*} P<0.05$, ${ }^{* *} P<0.01$, and ${ }^{* * *} P<0.001$ vs. medium control (a, c) or vs. LP1569 alone (b) or vs. phosphate-buffered saline (PBS; d). production by DCs from C57BL/6 mice (Figure 5a). We next demonstrated that the lipopeptide specifically activated TLR2 by stimulating murine DCs with LP1569 in the presence and absence of a TLR2 blocking antibody. LP1569 induced TNF- $\alpha$ production that was blocked by anti-TLR2 (Figure 5b). LP1569 also stimulated TNF $\alpha$ and IL-6 production by human peripheral blood mononuclear cells (Figure 5c). Finally, we demonstrated that LP1569 induced proinflammatory cytokine production in vivo. Injection of mice with LP1569 resulted in a significant enhancement of serum concentrations of IL-12 and IL-6 over that observed in mice injected with PBS (Figure 5d). These findings demonstrate that the synthetic peptide LP1569 is a TLR2 agonist and activates innate immune responses in vitro and in vivo.

\section{LP1569 indirectly promotes IFN- $\gamma$ and IL-17 production by T cells}

We have shown that BP1569 and LP1569 promote inflammatory cytokine production by DCs, including IL-12, IL-6, and IL-23, that are associated with the induction or expansion of Th1 and Th17 cells. In addition, we have previously reported that IL- $1 \beta$ and IL- 23 can induce IL-17 production by $\gamma \delta$ T cells in the absence of $\mathrm{T}$-cell receptor engagement. ${ }^{24}$ There is also controversial evidence that $\gamma \delta$ T cells can respond directly to TLR2 ligands alone or in the presence of IL-23. ${ }^{25}$ The $\gamma \delta$ T cells are an important source of IL-17 and IFN- $\gamma$ in immunity to bacterial infections, ${ }^{26}$ and TLR2 agonists may be directly or indirectly involved in their activation. Stimulation of spleen cells with LP1569 induced the production of IFN- $\gamma$ detected by enzyme-linked immunosorbent assay (ELISA) that was inhibited upon coincubation with an anti-IL-12p40 but not an antiIL-23p19 antibody, indicating a role for LP1569-driven IL-12p70 in IFN- $\gamma$ production (Figure 6a). Furthermore, LP1569 induced IL-17 production by spleen cells following addition of exogenous IL-23 (Figure 6b). In contrast, LP1569 did not induce production of the Th2 cytokine IL-13 (data not shown). Intracellular cytokine staining and fluorescenceactivated cell sorting analysis revealed that $\mathrm{CD}^{+}$and $\mathrm{CD}^{+}{ }^{+} \mathrm{T}$ cells produce IFN- $\gamma$ following stimulation of the spleen cells with LP1569 that was slightly augmented by addition of IL-1 $\beta$ (Figure $\mathbf{6 c}, \mathbf{d}$ ). Furthermore, intracellular cytokine staining showed that the combination of LP1569 and IL-23, but not LP1569 or IL-23 alone, induced a clear population of IL-17-secreting $\gamma \delta \mathrm{T}$ cells (Figure 6e). These findings demonstrate that LP1569 indirectly enhances IFN- $\gamma$ and IL-17 production by T cells in vitro and may therefore have potential as an adjuvant for enhancing innate and adaptive immunity in vivo.

\section{LP1569 is an effective adjuvant for promoting protective immunity against $B$. pertussis}

Having shown that LP1569 has immunostimulatory activity, promoting innate cytokines that drive T-cell responses, we assessed its adjuvant activity in vivo using protective antigens from B. pertussis in an established respiratory infection model. Our previous studies using this model have demonstrated a critical role for Th1 and Th17 cells in natural and 

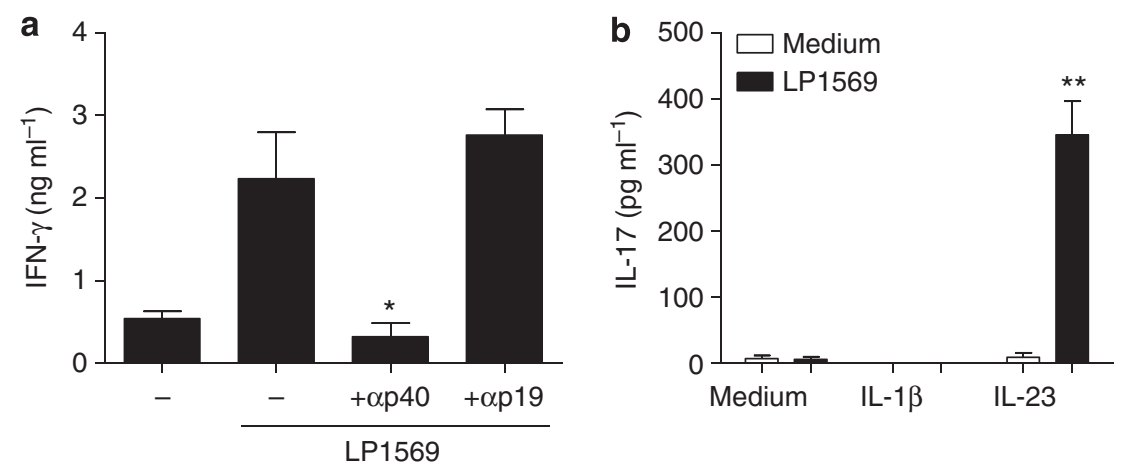

C

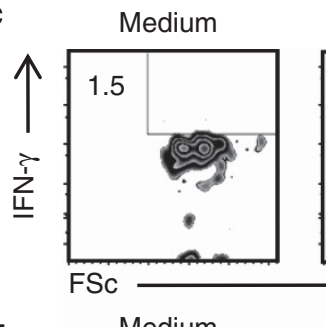

LP1569
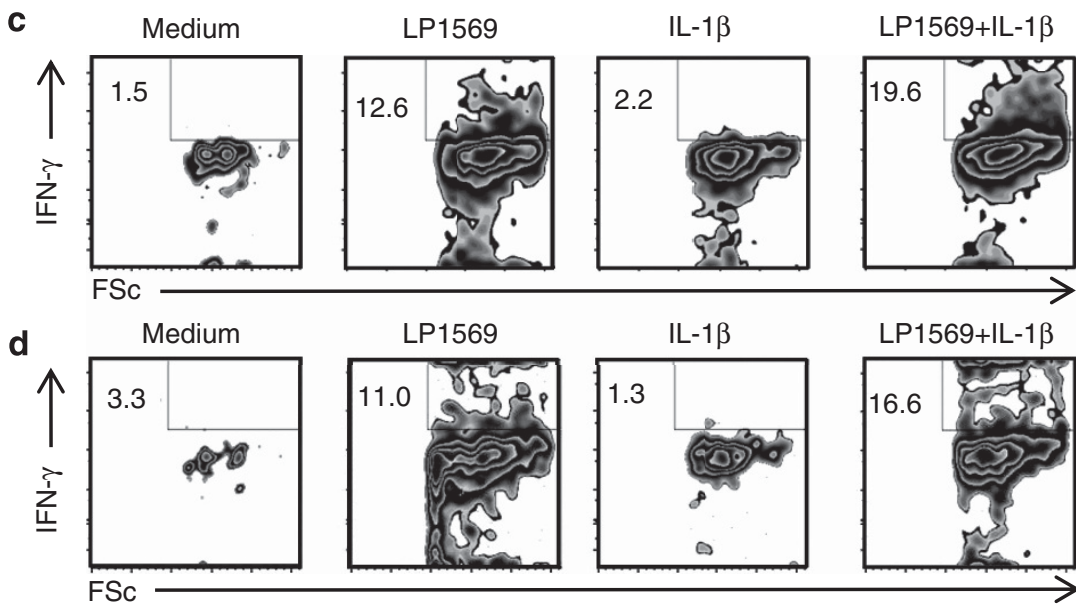

e

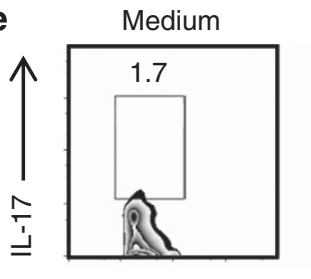

LP1569

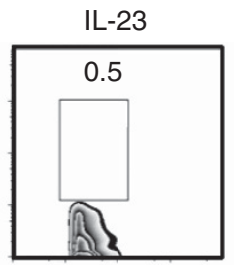

LP1569+IL-23

$\operatorname{TCR} \delta$
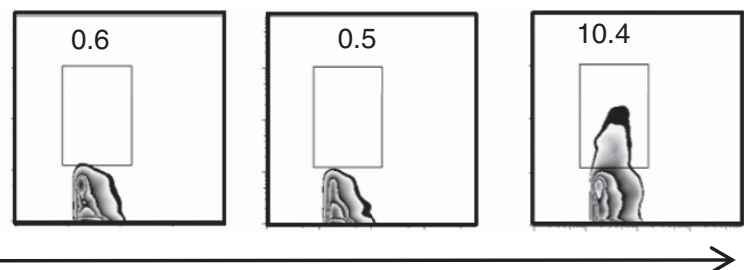

Figure 6 LP1569 enhances activation of $\gamma \delta$ T cells and CD4 T cells. Spleen cells from C57BL/6 mice were stimulated with (a) LP1569 (100 $\left.\mathrm{ng} \mathrm{ml} \mathrm{I}^{-1}\right)$ or medium with or without anti-IL-12p40 ( $\alpha$ p40) or anti-IL-23p19 ( $\alpha \mathrm{p} 19)$ blocking antibodies $\left(10 \mu \mathrm{g} \mathrm{ml}^{-1}\right)$ (b) or with interleukin (IL)-23 or IL-1 $\beta$ (10 ng ml ${ }^{-1}$ ). After $72 \mathrm{~h}$, supernatants were tested for IL-17 and interferon- $\gamma$ (IFN- $\gamma$ ) by enzyme-linked immunosorbent assay (ELISA). Intracellular cytokine staining for IL-17 or IFN- $\gamma$ was performed on spleen cells stimulated for 3 days with LP1569 $\left(100 \mathrm{ng} / \mathrm{ml}^{-1}\right)$ with or without IL-1 $\beta$ or IL-23 and for the final $4 \mathrm{~h}$ with brefeldin A. Cells were gated on (c) CD4 T cells, (d) CD8 T cells, or (e) $\gamma \delta$ T cells. TCR, T-cell receptor. Results in $\mathbf{a}$ and $\mathbf{b}$ are mean $\pm 1 \mathrm{~s}$.e.m. cytokine concentrations for triplicate cultures and are representative of three independent experiments. ${ }^{\star} P<0.05$ and ${ }^{\star *} P<0.01$ vs. LP1569 alone.

vaccine-induced immunity to $B$. pertussis. ${ }^{9}$ Mice were immunized with the $B$. pertussis antigens, filamentous hemagglutinin (FHA), detoxified pertussis toxin (PT), and pertactin alone or with LP1569 or with PBS only and boosted 5 weeks later. Mice were challenged by aerosol exposure to live B. pertussis 2 weeks after the second immunization. Assessment of colony-forming unit (CFU) counts in the lungs revealed that immunization with $B$. pertussis antigens without an adjuvant conferred limited protection against $B$. pertussis challenge (Figure 7a). In contrast, immunization with the experimental $\mathrm{Pa}$ formulated with LP1569 conferred a high level of protection against $B$. pertussis; bacteria were undetectable in immunized mice at 3,7 , and 10 days after challenge (Figure 7a).

We assessed antibody and T-cell responses specific for the $B$. pertussis antigen FHA in immunized mice on the day of challenge. The results revealed that immunization with $B$. pertussis antigens alone induced weak FHA-specific serum IgG1 and undetectable IgG2a. In contrast, immunization with B. pertussis antigens in combination with LP1569 generate high FHA-specific IgG2a titers in serum (Figure 7b). Furthermore, the experimental Pa with LP1569 generated potent Th1 and Th17 responses, with high concentrations of IFN- $\gamma$ and IL-17 detected in supernatants of FHA-stimulated spleen cells from immunized mice (Figure 7c). In contrast, immunization with the $B$. pertussis antigens in the absence of the lipopeptide generated Th2-type responses, with high IL-5, but substantially lower concentrations of IL-17 and IFN- $\gamma$ than that generated with the experimental vaccine formulated with LP1569.

We next assessed the efficacy of our experimental vaccine formulated with the TLR2 agonist LP1569 in comparison with 

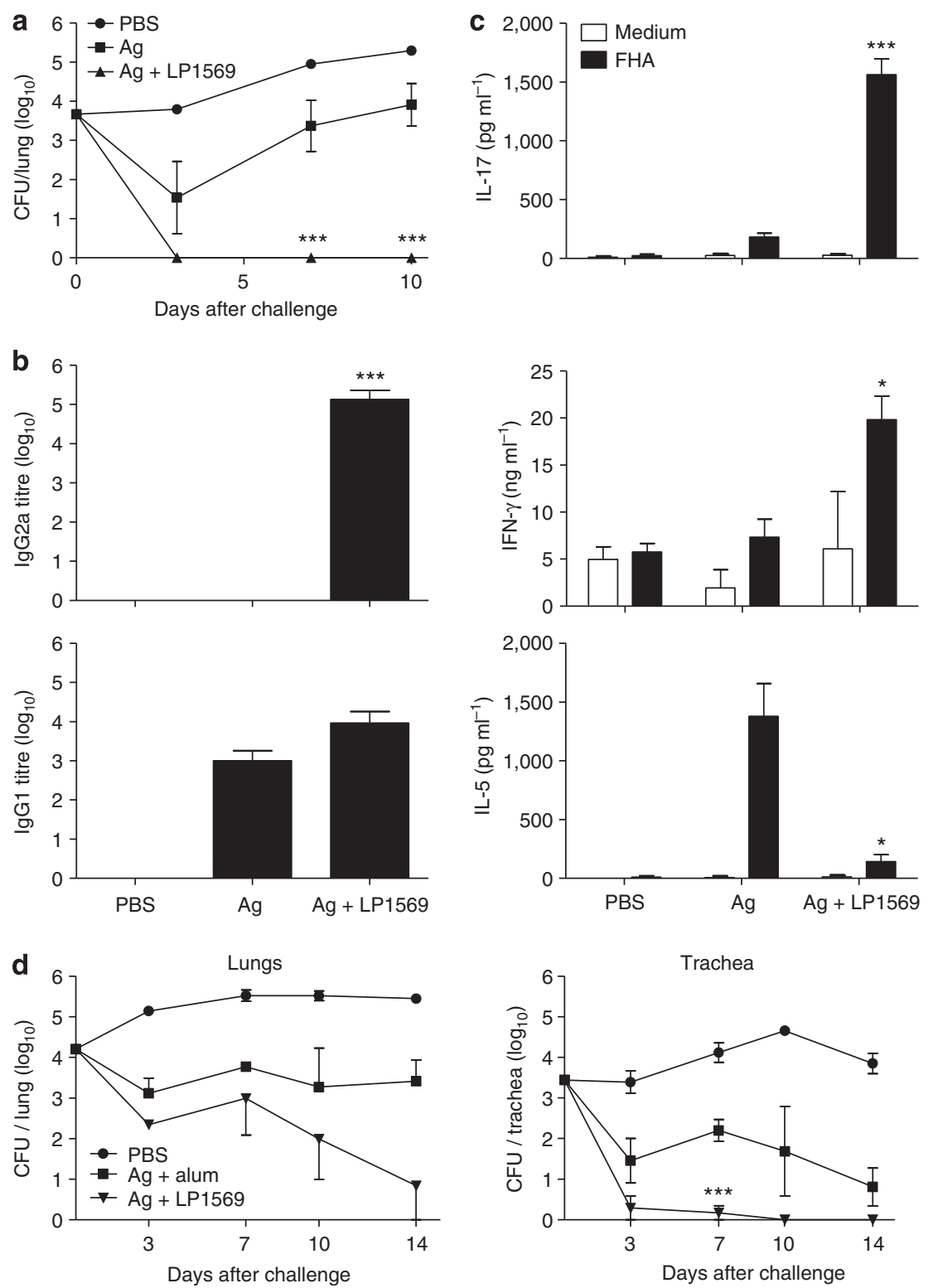

Figure 7 LP1569 acts as an adjuvant for an experimental acellular pertussis vaccine and promotes protective cellular immunity against Bordetella pertussis. C57BL/6 mice were immunized twice ( 0 and 5 weeks) with detoxified pertussis toxin (PTd), filamentous hemagglutinin (FHA), and pertactin alone or formulated with LP1569 or phosphate-buffered saline (PBS) as control. At 2 weeks after the second immunization, mice were challenged by aerosol exposure to live B. pertussis. (a) Colony-forming unit (CFU) counts were performed on lung homogenates from 4 mice in each group at 3,7 , and 10 days after challenge. (b, c) On the day of challenge, serum and spleen cells were prepared from four mice in each experimental group. (b) Serum FHAspecific IgG1 and IgG2a antibody titers were determined by enzyme-linked immunosorbent assay (ELISA). (c) Spleen cells from immunized mice were stimulated with FHA and after 3 days, interleukin (IL)-17, interferon- $\gamma$ (IFN- $\gamma$ ), and IL-5 concentrations in supernatants were quantified by ELISA. (d) C57BL/6 mice were immunized twice (0 and 4 weeks) with recombinant PT (rPT) and FHA formulated with LP1569 or with alum. At 2 weeks after the second immunization, mice were challenged by aerosol exposure to live $B$. pertussis. CFU counts were performed on homogenates of lung or trachea from 4 mice in each group at $3,7,10$, and 14 days after challenge. Results in each panel are mean \pm 1 s.e.m. values for four mice per group and are representative of two independent experiments. ${ }^{*} P<0.05$ and ${ }^{* * *} P<0.001 \mathrm{vs}$. Ag alone or alum.

the same vaccine formulated with alum. Here we immunized mice with two antigens (recombinant PT and FHA), followed by a challenge that resulted in relatively high bacterial colonization of the respiratory tract to show fine differences between vaccines that are protective and highly protective. We found that immunization with the experimental Pa formulated with LP1569 conferred a higher level of protection against bacterial colonization of the lungs and trachea than in mice immunized with the same antigens formulated with alum (Figure 7d). This was particularly striking for the CFU counts in the trachea, where we observed almost complete clearance by day 3 in mice immunized with the vaccine formulated with LP1569, compared with more prolonged infection in mice immunized with the alum-adjuvanted vaccine. These findings 
demonstrate that LP1569 is a potent adjuvant for induction of Th1/Th17-type responses and protection against B. pertussis. Furthermore, an experimental vaccine formulated with the TLR2 agonist was more effective than an alum-formulated vaccine in preventing colonization of mice with $B$. pertussis.

\section{DISCUSSION}

In this study, we report for the first time the identification of novel TLR2 lipoprotein ligands from $B$. pertussis capable of activating innate immune responses that drive the induction of protective vaccine-induced adaptive immunity against $B$. pertussis. The proteins identified contain the unique $\mathrm{N}$-terminal signal peptide characteristic of bacterial lipoproteins from Gram-negative bacteria and we demonstrate that at least one of these proteins, BP1569, has potent immunostimulatory activity, driving DC maturation and proinflammatory cytokine production. Furthermore, we demonstrated that a corresponding synthetic lipopeptide agonist of TLR2 was an effective adjuvant for an experimental $\mathrm{Pa}$ that induced Th1 and Th17 responses and conferred a higher level of protection against $B$. pertussis infection in mice than an equivalent vaccine formulated with alum.

Host immunity to $B$. pertussis involves a combination of innate and adaptive immune responses. Although much of the research focus has been on the role of antibodies, recent studies have highlighted the importance of cellular immune responses, mediated by Th1 and Th17 cells, in both natural and vaccineinduced immunity to B. pertussis. ${ }^{6,727}$ The induction of Th1 and Th17 cells is dependent on DC maturation and production of innate cytokines, including IL-12, IL-1, IL-6, and IL-23 respectively. ${ }^{28}$ The induction of DC maturation and cytokine production is driven by activation through pattern recognition receptors, including TLRs and NOD-like receptors. Indeed, we and others have demonstrated that TLR4 plays a critical role in natural and vaccine-induced protective cellular immunity to $B$. pertussis. ${ }^{11,12}$ Surprisingly, during $B$. pertussis infection Th1 responses were stronger in TLR4-defective mice when compared with wild-type mice and this was attributed to weaker regulatory $\mathrm{T}$-cell responses because of the loss of TLR4 -induced innate IL-10. ${ }^{12}$ Nevertheless, these findings suggested that $B$. pertussis must contain other IL-12-inducing pathogen-associated molecular patterns that promote Th1 responses. This study demonstrates that TLR2 ligands including BP1569 induce potent IL-12 production by DCs and macrophages and promote Th1 responses to an experimental $\mathrm{Pa}$ and may also be drivers of protective Th1 responses in natural host immunity to $B$. pertussis.

In addition to the well-established function of Th1 cells in protective immunity to $B$. pertussis, by virtue of their role in macrophage activation and opsonizing antibody production, evidence is emerging that Th17 cells also play a role in immunity to $B$. pertussis through recruitment and activation of neutrophils in the respiratory tract. ${ }^{9}$ We have demonstrated that adenylate cyclase toxin from $B$. pertussis promotes Th17 responses by inducing IL-1 $\beta$ production via activation of the NLRP3 inflammasome and caspase-1 that is required for cleavage of pro-IL-1 $\beta .{ }^{14}$ The induction of pro-IL-1 $\beta$ is driven through a TLR-induced NF- $\kappa B$ pathway. IL- $1 \beta$ synergises with IL-23 to induce expansion of Th17 cells and promotes innate IL-17 production by $\gamma \delta \mathrm{T}$ cells. ${ }^{24}$ It has also been suggested that TLR2 agonists may directly induce IL-17 production by $\gamma \delta$ $\mathrm{T}$ cells by binding to TLR2 expressed on these cells. ${ }^{25}$ IL-17secreting $\gamma \delta$ T cells play an important role early in infection and help to drive IL-17 production by CD4 T cells. ${ }^{24}$ The present study demonstrated that the TLR2 lipopeptide LP1569 alone did not generate IL-17 production by $\gamma \delta$ T cells, but induced significant IL-17 production in synergy with IL-23. Furthermore, LP1569 indirectly enhanced IFN- $\gamma$ production by CD4 $\mathrm{T}$ cells in spleen cell cultures in vitro through IL-12 induction and enhanced Th1 responses in vivo when used as an adjuvant for an experimental Pa.

Immunity to infection by $B$. pertussis conferred by vaccination with $\mathrm{Pa}$ wanes significantly over a relatively short period; the efficacy of the vaccines has been shown to be as low as $24 \%$ in children aged 8-12 years ${ }^{4}$ that may explain the recent resurgence of whooping cough. Studies in mice and humans have shown that current $\mathrm{Pa}$ formulated with alum as the adjuvant preferentially induce Th2-type responses. ${ }^{2}$ However, recent studies in mice $^{9}$ and baboons ${ }^{29}$ have suggested that a failure of Pa to induce Th1 or Th17 responses may explain their limited ability to prevent infection and transmission with $B$. pertussis. Interestingly, when compared with an alumadjuvanted $\mathrm{Pa}$, we found that the experimental vaccine formulated with the TLR2 lipopeptide was particularly effective at preventing colonization of the trachea, whereas the alumadjuvanted vaccine was not. This is consistent with the study in the baboon model ${ }^{29}$ where immunization with a Pa formulated with alum failed to prevent nasopharyngeal carriage and transmission to naive hosts, whereas immunization with $\mathrm{Pw}$ or previous infection, which induces Th1 responses, was more effective at preventing infection as well as disease. Taken together with other reports, these findings demonstrate that the use of a Th1/Th17-promoting adjuvant such as the TLR2 agonists BP1569 or its corresponding synthetic lipopeptide LP1569 have the capacity to improve the efficacy of current Pa by promoting the induction of protective cellular immunity that prevents infection of the respiratory tract with $B$. pertussis. The TLR2 agonists identified in this study activated inflammatory cytokine production by human peripheral blood mononuclear cells as well as murine DCs in vitro, suggesting that translation of the findings across species may be more straightforward than for certain TLR agonists where there are differences in immunostimulatory activity in mice and humans. Furthermore, as the B. pertussis lipoprotein is an antigen as well as an adjuvant it has considerable potential for inclusion in an improved vaccine against $B$. pertussis in humans.

\section{METHODS}

Mice. $\mathrm{C} 57 \mathrm{BL} / 6$ mice and $\mathrm{C} 3 \mathrm{H} / \mathrm{HeJ}$ mice containing a mutation in the tlr4 gene were obtained from Harlan (Bicester, UK) and maintained at Trinity College Dublin in a specific pathogen-free facility. 
Reagents. Lipases from Aspergillus and Pseudomonas were obtained from Sigma-Aldrich (St Louis, MO). ELISA for TNF- $\alpha$, IL-23, IL-10, IL-12p70, IL-1 $\beta$, and IL-17 was obtained from R\&D Systems (Minneapolis, MN). ELISA for IFN- $\gamma$, IL-6, IL-5, and IL-12p40 was obtained from BD Biosciences (Franklin Lakes, NJ). Lipopeptide LP1569 was synthesized by EMC Microcollections (Tuebingen, Germany). Recombinant IL-1 $\beta$ and IL-23 were purchased from R\&D Systems, and anti-IL-12p40 and anti-IL-23p19 from BD Biosciences.

Cloning and purification of BP1569 and BP2992. DNA encoding BP1569 and BP2992 was amplified from B. pertussis genomic DNA and cloned into the pET21a bacterial expression vector (Invitrogen, Carlsbad, CA) following sequence verification. C-terminal histidine versions $(6 \times$ histidine tag) were generated in E. coli BL21 pLysS cells following $0.2 \mathrm{~mm}$ isopropyl $\beta$-D-1-thiogalactopyranoside induction for $18 \mathrm{~h}$ at $30^{\circ} \mathrm{C}$. Cells were lysed using Bugbuster (Novagen, Madison, WI) and proteins were subsequently purified by nickel affinity followed by diethylaminoethyl ion-exchange chromatography. Following desalting on PD10 columns (GE Healthcare, Buckinghamshire, UK), protein purity was determined by sodium dodecyl sulfate-polyacrylamide gel electrophoresis and Coomassie staining or western blotting for the histidine-tagged proteins.

Cell preparation and stimulation. Bone marrow-derived DCs were prepared by culturing bone marrow cells obtained from the femur and tibia of mice in complete RPMI (RPMI containing $10 \%$ fetal calf serum, $100 \mathrm{U} \mathrm{ml}^{-1}$ penicillin, $100 \mu \mathrm{g} \mathrm{ml}^{-1}$ streptomycin, $2 \mathrm{~mm}$ L-glutamine (Invitrogen), and $50 \mu \mathrm{M} 2-\mathrm{ME}$ (Sigma-Aldrich)) supplemented with $40 \mathrm{ng} \mathrm{ml}^{-1}$ granulocyte macrophage colony-stimulating factor. Cells were recultured with fresh medium containing $40 \mathrm{ng} \mathrm{ml}^{-1}$ granulocyte macrophage colony-stimulating factor every 3 days for a period of 8 days. DCs were cultured $1 \times 10^{6}$ cells per $\mathrm{ml} 24 \mathrm{~h}$ before stimulation. Spleen cells from $\mathrm{C} 3 \mathrm{H} / \mathrm{HeJ}$ mice were cultured at $2 \times 10^{6}$ cells per ml and stimulated with BP1569 $\left(100 \mathrm{ng} \mathrm{ml}^{-1}\right)$ for $2 \mathrm{~h}$, with or without addition of anti-TLR2 antibody (T2.5). For p38 activation assays, samples were lysed with RIPA buffer and sodium dodecyl sulfate-polyacrylamide gel electrophoresis was performed followed by western blotting with anti-phospho-p38 and $\beta$-actin antibodies (Cell Signalling, Beverly, MA). DCs $\left(1 \times 10^{6}\right.$ per ml $)$ or spleen cells $\left(1.5 \times 10^{6}\right.$ per $\left.\mathrm{ml}\right)$ from C57BL/6 mice were incubated with LP1569 at various concentrations for $6 \mathrm{~h}$ (DCs) or $72 \mathrm{~h}$ (spleen). Supernatants were recovered and TNF- $\alpha$, IL-12p40, IL-12p70, IL-6, and IL-1 $\alpha$ (DCs) or IFN- $\gamma$, IL-17, and IL-13 (spleen cells) concentrations were quantified by ELISA. Spleen cells were also incubated with IL-1 $\beta$, IL-23 (both $10 \mathrm{ng} \mathrm{ml}^{-1}$ ), anti-IL-12p40 or anti-IL-23p19 (both $10 \mu \mathrm{g} \mathrm{ml}^{-1}$ ) and for the final $4 \mathrm{~h}$ with brefeldin A $\left(10 \mu \mathrm{g} \mathrm{ml}^{-1}\right.$; Sigma-Aldrich) before staining for intracellular cytokines.

Luciferase assay. HEK293T cells and HEK293T cells stably expressing human TLR2 were transfected with an NF- $\kappa \mathrm{B}$ luciferase construct as described previously, ${ }^{30}$ and stimulated overnight with the indicated concentrations of BP1569.

Flow cytometry. Following stimulation, DCs were stained with CD11c (N418), major histocompatibility complex class II (M5/114.15.2), CD80 (clone 16-10A1), and CD86 (16-10A1). T cells were stained with T cell receptor- $\delta$ (GL3), CD4 (GK1.5), CD8 (53-6.7), IFN- $\gamma$ (XMG1.2), and IL-17 (TC11-18H10). Antibodies were purchased from eBioscience (San Diego, CA). Samples were analyzed with a FACSDIVA and FlowJo software (Miltenyi, Bergisch Gladbach, Germany).

Cytokine induction in vivo. $\mathrm{C} 3 \mathrm{H} / \mathrm{HeJ}$ mice were injected intraperitoneally with BP1569 $(70 \mu \mathrm{g})$ or PBS control. After $3 \mathrm{~h}$, serum cytokines were quantified by ELISA.

Antigenicity of BP1569. C3H/HeJ mice were injected in the footpad with BP1569 $(10 \mu \mathrm{g})$ in PBS or PBS only. After 7 days, the draining lymph node was harvested and cells were stimulated with medium or with either BP1569 $\left(2 \mu \mathrm{g} \mathrm{ml}^{-1}\right)$ or total heat-killed B. pertussis $\left(1-100 \times 10^{6}\right.$ per $\left.\mathrm{ml}\right)$. After 3 days of culture, the concentration of IFN- $\gamma$ in supernatants was quantified by ELISA.

Adjuvant activity of LP1569. Mice were immunized intraperitoneally twice (0 and 4 or 5 weeks) with an experimental laboratory $\mathrm{Pa}$ comprising the purified antigens, pertactin, detoxified PT, and FHA in PBS or with LP1569 or with the recombinant PT mutant (PT-9K/ 129A) and FHA (0.2 $\mu \mathrm{g}$ per mouse each), formulated with LP1569 (50 $\mu \mathrm{g}$ per mouse) or alum (100 $\mu \mathrm{g}$ per mouse). FHA was purchased from Kaketsuken (Kumamoto, Japan) and pertactin, PT, and recombinant PT were obtained from List Biological Laboratories (Campbell, CA). Antigen preparations were highly purified, as determined by sodium dodecyl sulfate gel chromatography. and were free of detectable LPS. PT was detoxified with formaldehyde as previously described. ${ }^{31}$ Mice were challenged with $B$. pertussis by exposure to an aerosol of $5 \times 10^{8}$ bacteria per $\mathrm{ml}$ and killed 2 weeks after second immunization.

B. pertussis respiratory challenge. Mice were infected with $B$. pertussis by exposure to an aerosol of live B. pertussis as previously described. $^{32}$ The course of $B$. pertussis infection was followed by performing CFU counts on lungs or tracheas from groups of four mice at intervals after challenge. The lungs and tracheas were aseptically removed and homogenized in 1 or $0.5 \mathrm{ml}$ respectively of sterile physiological saline with $1 \%$ casein on ice. Undiluted and serially diluted homogenate $(100 \mu \mathrm{l})$ from individual lungs/trachea were spotted in triplicate onto Bordet-Gengou agar plates, and the number of CFU was calculated after 5 days of incubation at $37^{\circ} \mathrm{C}$. The limit of detection was $2 \mathrm{CFU}$ per lung or trachea for groups of four mice at each time point.

T-cell cytokine production. Spleen cells $\left(2 \times 10^{6}\right.$ per $\left.\mathrm{ml}\right)$ from immunized mice were cultured at $37^{\circ} \mathrm{C}$ and $5 \% \mathrm{CO}_{2}$ with heat-killed B. pertussis, purified FHA, or medium only (negative control). Supernatants were removed after $72 \mathrm{~h}$ and IL-5, IL-13, IL-17, and IFN $-\gamma$ concentrations determined by two-site ELISA.

FHA-specific antibody production. Serum antibody responses to B. pertussis were quantified by ELISA using plate-bound FHA $\left(1 \mu \mathrm{g} \mathrm{ml}^{-1}\right)$. Bound antibodies were detected using biotin-conjugated anti-mouse IgG1 or IgG2a (BD) and peroxidase-conjugated streptavidin (BD Pharmingen, Franklin Lakes, NJ). Antibody levels are expressed as the mean end point titer ( \pm s.e.), determined by extrapolation of the linear part of the titration curve to 2 s.e. above the background value obtained with nonimmune mouse serum.

Statistical analysis. Statistics were calculated using Prism 5 (GraphPad Software, San Diego, CA). Comparisons were made by Student's $t$-test or for multiple cohorts by analysis of variance.

\section{ACKNOWLEDGMENTS}

This work was supported by Science Foundation Ireland grants (07/SRC/ B1144 and 11/ PI/1036) to K.H.G.M.

\section{DISCLOSURE}

K.H.G.M. is a co-founder and shareholder in Opsona Therapeutics and TriMod Therapeutics, University Spin-out companies involved in the development of Immunotherapeutics. The other authors declared no conflict of interest.

c 2015 Society for Mucosal Immunology

\section{REFERENCES}

1. Cherry, J.D. The present and future control of pertussis. Clin. Infect. Dis. 51, 663-667 (2010).

2. Higgs, R., Higgins, S.C., Ross, P.J. \& Mills, K.H. Immunity to the respiratory pathogen Bordetella pertussis. Mucosal Immunol. 5, 485-500 (2012). 
3. Mooi, F.R., Van Der Maas, N.A. \& De Melker, H.E. Pertussis resurgence: waning immunity and pathogen adaptation - two sides of the same coin. Epidemiol. Infect. 142, 1-10 (2013).

4. Klein, N.P., Bartlett, J., Rowhani-Rahbar, A., Fireman, B. \& Baxter, R. Waning protection after fifth dose of acellular pertussis vaccine in children. N. Engl. J. Med. 367, 1012-1019 (2012).

5. Ryan, E.J., Nilsson, L., Kjellman, N., Gothefors, L. \& Mills, K.H. Booster immunization of children with an acellular pertussis vaccine enhances Th2 cytokine production and serum IgE responses against pertussis toxin but not against common allergens. Clin. Exp. Immunol. 121, 193-200 (2000).

6. Ryan, M. et al. Distinct T-cell subtypes induced with whole cell and acellular pertussis vaccines in children. Immunology 93, 1-10 (1998).

7. Redhead, K., Watkins, J., Barnard, A. \& Mills, K.H. Effective immunization against Bordetella pertussis respiratory infection in mice is dependent on induction of cell-mediated immunity. Infect. Immun. 61, 3190-3198 (1993).

8. Ausiello, C.M., Urbani, F., la Sala, A., Lande, R. \& Cassone, A. Vaccine- and antigen-dependent type 1 and type 2 cytokine induction after primary vaccination of infants with whole-cell or acellular pertussis vaccines. Infect. Immun. 65, 2168-2174 (1997).

9. Ross, P.J. et al. Relative contribution of Th1 and Th17 cells in adaptive immunity to Bordetella pertussis: towards the rational design of an improved acellular pertussis vaccine. PLoS Pathog. 9, e1003264 (2013).

10. Kumar, H., Kawai, T. \& Akira, S. Pathogen recognition by the innate immune system. Int. Rev. Immunol. 30, 16-34 (2011).

11. Higgins, S.C., Jarnicki, A.G., Lavelle, E.C. \& Mills, K.H. TLR4 mediates vaccine-induced protective cellular immunity to Bordetella pertussis: role of IL-17-producing T cells. J. Immunol. 177, 7980-7989 (2006).

12. Higgins, S.C. et al. Toll-like receptor 4-mediated innate IL-10 activates antigen-specific regulatory $T$ cells and confers resistance to Bordetella pertussis by inhibiting inflammatory pathology. J. Immunol. 171, 3119-3127 (2003).

13. Donnelly, S., Loscher, C.E., Lynch, M.A. \& Mills, K.H. Whole-cell but not acellular pertussis vaccines induce convulsive activity in mice: evidence of a role for toxin-induced interleukin-1 beta in a new murine model for analysis of neuronal side effects of vaccination. Infect. Immun. 69, 4217-4223 (2001).

14. Dunne, A. et al. Inflammasome activation by adenylate cyclase toxin directs Th17 responses and protection against Bordetella pertussis. J. Immunol. 185, 1711-1719 (2010).

15. Morr, M., Takeuchi, O., Akira, S., Simon, M.M. \& Muhlradt, P.F. Differential recognition of structural details of bacterial lipopeptides by toll-like receptors. Eur. J. Immunol. 32, 3337-3347 (2002).

16. Takeuchi, O. et al. Discrimination of bacterial lipoproteins by Toll-like receptor 6. Int. Immunol. 13, 933-940 (2001).

17. Takeuchi, O. et al. Cutting edge: role of Toll-like receptor 1 in mediating immune response to microbial lipoproteins. J. Immunol. 169, 10-14 (2002).
18. Braun, V. \& Rehn, K. Chemical characterization, spatial distribution and function of a lipoprotein (murein-lipoprotein) of the $E$. coli cell wall. The specific effect of trypsin on the membrane structure. Eur. J. Biochem. 10, 426-438 (1969).

19. Hantke, K. \& Braun, V. Covalent binding of lipid to protein. Diglyceride and amide-linked fatty acid at the $\mathrm{N}$-terminal end of the murein-lipoprotein of the Escherichia coli outer membrane. Eur. J. Biochem. 34, 284-296 (1973).

20. Braun, V. Covalent lipoprotein from the outer membrane of Escherichia coli. Biochim. Biophys. Acta 415, 335-377 (1975).

21. Jin, M.S. et al. Crystal structure of the TLR1-TLR2 heterodimer induced by binding of a tri-acylated lipopeptide. Cell 130, 1071-1082 (2007).

22. Fennelly, N.K. et al. Bordetella pertussis expresses a functional type III secretion system that subverts protective innate and adaptive immune responses. Infect. Immun. 76, 1257-1266 (2008).

23. Punturieri, A., Copper, P., Polak, T., Christensen, P.J. \& Curtis, J.L. Conserved nontypeable Haemophilus influenzae-derived TLR2-binding lipopeptides synergize with IFN-beta to increase cytokine production by resident murine and human alveolar macrophages. J. Immunol. 177, 673-680 (2006).

24. Sutton, C.E. et al. Interleukin-1 and IL-23 induce innate IL-17 production from gamma delta T cells, amplifying Th17 responses and autoimmunity. Immunity 31, 331-341 (2009).

25. Martin, B., Hirota, K., Cua, D.J., Stockinger, B. \& Veldhoen, M. Interleukin17-producing gammadelta $T$ cells selectively expand in response to pathogen products and environmental signals. Immunity 31, 321-330 (2009).

26. Sutton, C.E., Mielke, L.A. \& Mills, K.H. IL-17-producing gammadelta Tcells and innate lymphoid cells. Eur. J. Immunol. 42, 2221-2231 (2012).

27. Mahon, B.P., Brady, M.T. \& Mills, K.H. Protection against Bordetella pertussis in mice in the absence of detectable circulating antibody: implications for long-term immunity in children. J. Infect. Dis. 181, 2087-2091 (2000)

28. Walsh, K.P. \& Mills, K.H. Dendritic cells and other innate determinants of T helper cell polarisation. Trends Immunol. 34, 521-530 (2013).

29. Warfel, J.M., Zimmerman, L.I. \& Merkel, T.J. Acellular pertussis vaccines protect against disease but fail to prevent infection and transmission in a nonhuman primate model. Proc. Natl. Acad. Sci. USA 111, 787-792 (2014).

30. Carpenter, S. et al. TRIL, a functional component of the TLR4 signaling complex, highly expressed in brain. J. Immunol. 183, 3989-3995 (2009).

31. Sutherland, J.N., Chang, C., Yoder, S.M., Rock, M.T. \& Maynard, J.A. Antibodies recognizing protective pertussis toxin epitopes are preferentially elicited by natural infection versus acellular immunization. Clin. Vaccine Immunol. 18, 954-962 (2011).

32. McGuirk, P., McCann, C. \& Mills, K.H. Pathogen-specific T regulatory 1 cells induced in the respiratory tract by a bacterial molecule that stimulates interleukin 10 production by dendritic cells: a novel strategy for evasion of protective Thelper type 1 responses by Bordetella pertussis. J. Exp. Med. 195, 221-231 (2002). 